Check for updates

1 Epidemiology, Biostatistics and Prevention Institute, University of Zurich, Hirschengraben 84, 8001 Zurich, Switzerland

2 Population Heath Laboratory (\#PopHealthLab), University of Fribourg, Fribourg, Switzerland

3 School of Population and Global Health, McGill University, Montreal, Canada

miloalan.puhan@uzh.ch Cite this as: BMJ 2021;373:n917 http://dx.doi.org/10.1136/bmj.n917 Published: 12 April 2021
COVID ANTIBODIES FROM INFECTION OR VACCINATION

\section{Overcoming spectrum bias for accurate SARS-CoV-2 seroprevalence estimates}

\author{
Milo A Puhan, ${ }^{1}$ Arnaud Chiolero, ${ }^{2,3}$ Jan Fehr, ${ }^{1}$ Stéphane Cullati ${ }^{2}$, On behalf of the Corona Immunitas \\ Research Group
}

Repeated population based SARS-CoV-2 seroprevalence studies provide evidence on how immunity develops in a population. They are especially relevant now, as we are at a turning point with vaccines that greatly accelerate the development of immunity.

A surprisingly low seroprevalence of $14 \%$ was recently reported for the UK. ${ }^{1}$ The cumulative proportion of confirmed infected people in the UK $(6.3 \%)$ is very close to that of Switzerland $(6.6 \%){ }^{2}$ Assuming that only around one in 3-4 infected people are diagnosed, ${ }^{3}$ a seroprevalence of $20-25 \%$ would be expected, without people who have been vaccinated. This is consistent with what has been observed for different cantons of Switzerland in the Corona Immunitas programme. ${ }^{4}$ Switzerland is experiencing a slow start to its vaccination programme, and the effect of vaccination on seroprevalence estimates is negligible. In the UK, however, with 33 doses given per 100 people ${ }^{2}$ and the cumulative proportion of infected people, the seroprevalence should be higher than $14 \%$.

One possible reason for this low estimate is the use of self-administered lateral flow tests in the React-2 study, so seroprevalence estimates were adjusted for the sensitivity (84.4\%) and specificity (98.6\%) of these tests. ${ }^{2}$ The test performance estimates were based on the analyses of clinically ill people with SARS-CoV-2 infection (cases) and pre-pandemic samples (controls), leading to a substantial spectrum bias. ${ }^{5}$ This is a major problem for population based studies as many people with past infections have had a mild or asymptomatic course, which is more difficult to detect than moderate to severe infections.

Commercially available tests based on venous blood miss up to $40 \%$ of infections, ${ }^{6}$ and lateral flow tests are clearly even less accurate and probably have a sensitivity lower than $84.4 \%$ in population based samples. In Switzerland, Corona Immunitas chose a sophisticated test, with test performance estimates based on a population based sample. ${ }^{6}$ This is more laborious and costlier but gives a more accurate picture of immunity development in a population.

Competing interests: None declared.

Full response at: https://www.bmj.com/content/372/bmj.n561/rr.

Wise J. Covid-19: One in seven people in England have antibodies from infection or vaccination, finds study. BMJ 2021;372:n561. doi: 10.1136/bmj.n561 pmid: 33632718

2 Our World in Data. United Kingdom: coronavirus pandemic country profile. https://ourworldindata.org/coronavirus/country/united-kingdom?country=GBR CHE.
3 Office for National Statistics. Coronavirus (covid-19) infection survey antibody data for the UK, March 2, 2021, https://www.ons.gov.uk/peoplepopulationandcommunity/healthandsocialcare/conditionsanddiseases/articles/coronaviruscovid19infectionsurveyantibodydatafortheuk/2march2021.

4 Corona Immunitas programme of the Swiss School of Public Health. https://www.corona-immunitas.ch/en/.

5 Deeks JJ, Dinnes J, Takwoingi Y, etalCochrane COVID-19 Diagnostic Test Accuracy Group. Antibody tests for identification of current and past infection with SARS-CoV-2. Cochrane Database Syst Rev 2020;6:CD013652. doi: 10.1002/14651858.CD013652. pmid: 32584464

6 Fenwick C, Croxatto A, Coste AT, etal. Changes in SARS-CoV-2 spike versus nucleoprotein antibody responses impact the estimates of infections in population-based seroprevalence studies. J Virol 2021;95:e01828-20.doi: 10.1128/JVI.01828-20. pmid: 33144321

This article is made freely available for use in accordance with BMJ's website terms and conditions for the duration of the covid-19 pandemic or until otherwise determined by BMJ. You may use, download and print the article for any lawful, copyright notices and trade marks are retained. non-commercial purpose (including text and data mining) provided that all 